\title{
Life Span and Resiliency Theory: A Critical Review
}

\author{
Alexa Smith-Osborne
}

\begin{abstract}
Theories of life span development describe human growth and change over the life cycle (Robbins, Chatterjee, \& Canda, 2006). Major types of developmental theories include biological, psychodynamic, behavioral, and social learning, cognitive, moral, and spiritual, and those influenced by systems, empowerment, and conflict theory. Life span development theories commonly focus on ontogenesis and sequential mastery of skills, tasks, and abilities. Social work scholars have pointed out that a limitation of life span and other developmental theory is lack of attention to resilience (Greene, 2007; Robbins et al., 1998).
\end{abstract}

The concept of resilience was developed to "describe relative resistance to psychosocial risk experiences" (Rutter, 1999b, p. 119). Longitudinal studies focused on typical and atypical child development informed theory formulation in developmental psychopathology (Garmezy \& Rutter, 1983; Luthar, Cichetti, \& Becker, 2000) and in an evolving resilience model (Richardson, 2002; Werner \& Smith, 1992). Research on resilience has found a positive relationship between a number of individual traits and contextual variables and resistance to a variety of risk factors among children and adolescents. More recently, resilience research has examined the operation of these same factors in the young adult, middle-age, and elder life stages.

This article examines the historical and conceptual progression of the two developmental theories-life span and resiliency-and discusses their application to social work practice and education in human behavior in the social environment.

Keywords: Life span, resiliency theory, life cycle, critique

$\mathrm{T}$ heories of life span development describe human growth and change over the life cycle (Robbins, Chatterjee, \& Canda, 2006). Major types of developmental theories include biological, psychodynamic, behavioral and social learning, cognitive, moral and spiritual, and those influenced by systems, empowerment, and conflict theory. Life span development theories commonly focus on ontogenesis and the sequential mastery of skills, tasks, and abilities.

Alexa Smith-Osborne, Ph.D. is assistant professor at The University of Texas at Arlington School of Social Work, Arlington, TX 76019. 
The major theories address the entire life cycle, from prenatal or birth to death, but they often focus in-depth on particular age periods, referred to as life stages. Some theorists within this field have focused more exclusively on a single life stage (Vaillant, 1993) or on a macro-level view of developmental traits that characterize an age cohort with defined ranges of birth dates or historical/cultural periods of primary influence on development (Strauss \& Howe, 1991). For purposes of this paper, only a segment of life span theory can be addressed. Therefore, this paper focuses on personality and psychosocial theories, which form the historical foundation for much of the other life span theories.

Resiliency theory is an emerging theoretical perspective that has been developed within developmental psychopathology and ecosystems perspectives and is influenced by stress and coping theories. Although this theory has not been explicitly developed as an outgrowth of life span theory, it is developmental in focus, and theory-driven research typically examines a specific chronological life stage as a starting point. This theoretical framework addresses health development of at-risk populations, and overcoming stress and adversity to achieve functional outcomes either during a life stage, a specific trajectory (e.g., educational or deviancy), or throughout the life span. The initial focus of theory development has been on childhood and adolescence and associations of traits and events at these life stages with outcomes later in life. Some recent research in this field has applied resiliency constructs to adults at risk (Daining, 2005; Smith, 2003; SmithOsborne, 2006).

\section{Historical Context}

The notion that life can be understood as a series of significant and sequential stages can be traced to the earliest human civilizations and has appeared consistently in literary, religious, and philosophical writings throughout history (Erikson, 1968; Robbins et al., 1998). The scientific approach to human development throughout the life cycle was stimulated by the emergence of evolutionary theory at the turn of the century (Darwin, 1872), which led to the development of biologically focused maturational and psychosexual perspectives, such as those of G. Stanley Hall in 1904, Sigmund Freud in 1905, and Arnold Gesell in 1925. These seminal theories challenged the Victorian (and earlier) conception of children as little adults, and childhood as a time of relative stability, while the children were simply waiting to grow physically (Colby, 1970; Karl, 1964).

These theories also established the conceptualization of human development as occurring in a series of essentially stable stages, with periods of instability during transitions between stages and the mastery of stage-specific skills or conflicts as the foundation for progress to the next stage (Hoffman, Paris, Hall, \& Schell, 1988).

Freudian theory came to dominate much of human development theory and clinical practice in the early $20^{\text {th }}$ century, with several of Freud's students, notably Jung and Erikson, expanding on his concepts on the basis of their own clinical and cross-cultural experiences. These amplifications of Freudian theory occurred against the backdrop of the rise of fascism, the Holocaust, and World War II. The originator of what is now called the life span approach to human psychological development, Erik Erikson, had been a student of Freud's and trained as a psy- 
choanalyst in Germany. Erickson fled Nazi Germany in 1939 to immigrate to America, where he expanded Freud's stages to apply to the entire life span, emphasizing psychosocial, rather than biological drive theory.

Resiliency theory, in contrast, originated on the basis of prospective longitudinal research on cohorts of children at risk (Garmezy, 1993; Rutter, Quinton, \& Hill, 1990; Werner \& Smith, 1982, 1992), rather than on the basis of individual clinicians' observations and case studies. Such studies were informed by prevention science (Greene, 2007) and the application of the epidemiological concepts of immunity and resistance to disease to human development and psychopathology (Thoits, 1983). In particular, Werner and Smith's longitudinal study of 698 infants, many of Hawaiian and Asian descent, provided a major empirical basis for the inception of resiliency constructs and hypotheses for further testing, as did Rutter's work with early onset mental disorders and with institutionalized Romanian children (e.g., Rutter, 1983; Rutter et al., 1990). Resiliency theory's salutogenic orientation has been heavily influenced by the Hawaiian study's focus on those in childhood adversity who overcome the odds by the time they reach adulthood. The initial formulation of theoretical concepts and constructs based on this research proceeded within the developmental psychopathology framework in psychiatry (e.g., Rutter, 1987) and developmental psychology (e.g., Garmezy, Masten, \& Tellegen, 1984) and within family stress and adjustment theory (e.g., McCubbin \& Dahl, 1976; McCubbin \& Patterson, 1983) in social work. Much of the seminal research in this field was begun in the late 1950s (e.g., Werner \& Smith began their study in 1955) and initial findings were reported in the 1980s. Thus, this early theoretical development was situated historically in the postVietnam War and the post-colonial era of globalization, and it often focused on identifying factors in overcoming trauma and adverse events, such as warinduced family separations. Later, as social work educators and researchers gave more attention to salutogenic, strengths-based (Saleebey, 1997) theoretical models for practice, resiliency constructs were further developed within the ecological perspective (e.g., Fraser \& Galinsky, 1997; Gilgun, 1996) in social work theory, rather than in life span theory. Social workers have continued to draw on resiliency theory constructs and empirical findings in research (e.g., Herrenkohl, Hill, Chung, Guo, Abbott, \& Hawkins, 2003) and in human behavior and practice texts (e.g., Haight \& Taylor, 2007; Johnson, 2004; Thomlison, 2007), either within the ecological perspective (e.g., Haight \& Taylor) or, more commonly, outside a specified theoretical frame of reference. Furthermore, some social workers have explicitly identified and used resiliency theory as a theoretical framework, independent of other perspectives, for education (Greene, 2007) and research (SmithOsborne, 2005a, 2006; Ungar, 2004).

\section{THEORETICAL CONCEPTS AND CRITICAL ANALYSIS}

\section{Life Span Theory}

Life span theory utilizes the central concept of ontogenesis, the chronological unfolding of human development (Gunnar \& Thelen, 1989; Thelen \& Smith, 1994), which includes both change in size and change in the complexity and differentiation of function (e.g., the change in motor reflexes at various stages in 
life). Some theorists include deterioration or diminishment in size and function, particularly if the focus is on aging and the adult life cycle, as well as accretion or augmentation (Jung, 1965; Newman \& Newman, 1975; Santrock, 1989).

Erikson (1950) proposed the concept of "epigenesis" to convey that human development unfolds from part to whole, with elements of the chronologically appropriate ability or personality feature gradually emerging in a prescribed sequence until the functional whole was achieved. The term has since been used within the developmental psychopathology theoretical perspective to also apply to the chronological unfolding over the life span of the disease process, such as schizophrenia (e.g., Cannon, Rosso, Bearden, Sanchez, \& Hadley, 1999). He saw this emergence as occurring within an interactional and adaptive framework, within which the individual develops through interaction and adaptation to the immediate social environment as well as to the larger society, culture, and historical context. Thus, Erikson postulated that mutual responsiveness on the part of both the individual and society was necessary for optimal development.

Another key life span concept associated with the work of Freud and Erikson is the life stage. The life stage is seen as an age-related period of life characterized by predictable features, tensions, and changes and leads into a subsequent stage. Erikson formulated the notion of the psychosocial crisis, a period of tension and disorganization centered on a stage-specific theme, the resolution of which was the goal of the transition phase from one stage to the next. Freud and Erikson conceptualized stages as prescriptive, in that their sequence was unvarying and defined optimal mature development, was associated with specific tensions/conflicts, and was prerequisite, in that each stage must be worked through and the associated conflicts resolved before successful transition to the next stage could be accomplished. Freud's and Erikson's life stage models are presented in Hoffman et al. (1988, pp. 30 and 32).

Erikson (1950) moved beyond Freud's life stage constructs in proposing that ego development in childhood is a process of identification, which he defined as internalization of another person's values and standards in an attempt to become like that person or parts of that person. It was in adolescence that Erikson observed (1968) the identity was formed through a process of:

repudiation and mutual assimilation of childhood identifications and their absorption in a new configuration, which in turn, is dependent on the process by which a society (often through subsocieties) identifies the young individual, recognizing him as somebody who had to become the way he is and who, being the way he is, is taken for granted. (p. 159)

In Erikson's theory, then, the concept of the mature ego identity as a complex sense of self, comprising societally-defined life roles as well as aspects of personality, is crucial. The "identity crisis" in adolescence is normative and revolves around issues of personal sameness and historical continuity, which serve as a link between the individual and the larger society. Prolonged adolescence, in Erikson's schema, provides a psychosocial moratorium in which the sexually mature individual engages in free role experimentation, sanctioned by society, in 
order to find a defined niche in society, while postponing adult sexual roles. Erickson saw this as a second period of delay in the life cycle, with the first being Freud's psychosexual moratorium of the latency life stage, which permits the young to learn the basics of society's work situations before embarking on mature sexual roles, such as spouse and parent. Erikson used the term identity diffusion, and later the term identity confusion (1968), to describe the state of mild confusion commonly experienced by adolescents in the process of identity formation. James Marcia (1980) developed this concept further to apply to adolescents who are not in an identity crisis, because they are not committing themselves to occupational or ideological goals and are not concerned about the situation.

Based on the mature and socially acceptable ego identity, the young adult, in Erikson's schema, could then take up the mature sexual role in seeking a spouse or intimate partner. In the middle adult stage, the individual was seen as transitioning to the ego strength made up of procreativity, productivity, and creativity, such as in forming a family and mentoring future generations on a personal, societal or even global level. The last stage of life was that of ego integrity, which involves the older adult's acceptance of his/her own live as meaningful and coherent, and the perspective that one has handled life's tasks in the best way possible under given circumstances.

Contemporary theorists have proposed expanded models, particularly in the adolescent and adult stages. Two such models, proposed by Vaillant (1993, p. 145) and Newman and Newman (1988, p. 45).

Erikson $(1982,1986,1988)$ built on his earlier work in the last life stage, as he and his wife reflected on their own adult development in later life, conceptualizing aging in terms of revisitation of earlier stages of development within his Stage 8 of Integrity vs. Despair.

Erikson and other psychodynamic theorists, such as Vaillant (1993), acknowledge developmental influences such as culture, race, and gender, but tend to view intrapsychic and biological factors, including IQ, as being more important to development.

Other theorists conceptualize human development as being more fluid throughout the life span, rather than the product of invariant and chronologically sequential stages, and as being more heavily influenced by social roles (Goffman, 1959; Neugarten, 1985), demographic variables, such as gender, race, or socioeconomic status, culture and historical "moment," and even the reciprocal, interactive effects of the immediate physical/social environment (Gunnar \& Thelen, 1989).

\section{Resiliency Theory}

The concept of resilience was developed to "describe relative resistance to psychosocial risk experiences” (Rutter, 1999b, p. 119). It has been further defined as "a dynamic process encompassing positive adaptation within the context of significant adversity" (Luthar, Cicchetti, \& Becker, 2000) and "the process of coping with adversity, change, or opportunity in a manner that results in the identification, fortification, and enrichment of resilient qualities or protective factors" 
(Richardson, 2002, p. 308). Research on stress reactions and recovery from stress, with implications for education, has also informed this theory (Benotsch et al., 2000; D’Imperio, Dubow, \& Ippolito, 2000; Dubow, Schmidt, McBride, Edwards, \& Merk, 1993; Dubow, Tisak, Causey, Hryshko, \& Reid, 1991; Fontana, Schwartz, \& Rosenheck, 1997; Garmezy \& Rutter, 1983; Golding, 1989; Keenan \& Newton, 1984; Lazarus, 1993; Lazarus \& Folkman, 1984). Thus, resilience is conceptualized as relative resistance to psychosocial stressors or adversity. Although varying models of resiliency have been tested, researchers and theorists agree that the construct is salient in the context of stress and adversity and is not operative in the absence of environmental stressors (Jew, Green, \& Kroger, 1999; Rutter, 1999).

The central constructs of the theory include risk factors/mechanisms, vulnerability factors, and protective factors/mechanisms. Risk factors and mechanisms have been conceptualized in alternate ways in the literature: either as 1) the events or conditions of adversity (for example, poverty) themselves for which there is empirical evidence of association with psychopathology, illness, or dysfunctional developmental outcomes or as 2) factors that operate to reduce resistance to stressors/adversity. Vulnerability factors are traits, genetic predispositions, or environmental and biological deficits (such as cognitive impairments) for which there is empirical evidence of heightened response, sensitivity, or reaction to stressors or risk factors. The constructs of vulnerability factors and risk factors are sometimes used interchangeably in the literature. Protective factors and mechanisms are traits, contextual characteristics, and interventions that operate to enhance or promote resistance, or which may moderate the effect of risk factors, and for which there is empirical evidence of association with health and functional developmental outcomes. Rutter (1987) suggests that protective mechanisms may operate in one of four ways to allow overcoming odds in the face of adversity: by reducing risk impact, by reducing negative chain reactions to risk factors, by promoting resiliency traits (i.e., the opposite of vulnerability factors, such as self-efficacy and optimism), and by setting up new opportunities for success. Reducing risk impact can occur not only by way of buffering events and social networks, but also by inoculation due to successful coping with earlier, milder stressful events. Protective and risk mechanisms have been found to vary according to the type of adversity, type of resilient outcome, and life stage under analysis; risk factors in one context may be protective in another (Rutter, 1999; Smith-Osborne, 2006; Ungar, 2004).

Research on resilience among children, adolescents, and young adults has found a positive relationship between spirituality, social support, social capital, income, and personal/family traits (e.g., hardiness, coherence, social competence and self-efficacy, normal attachment, healthy attributions, active stress appraisal, and coping), and resistance to a variety of risk factors, including psychiatric disorders and school failure/drop-out (Daining, 2005; Garmezy, 1991; Luthar et al., 2000; Masten \& Coatsworth, 1998; Richardson, 2002; Rutter, 1999a; Smith \& Carson, 1997; Werner, 1992). Research on military families dealing with war-induced separation and trauma has found associations between resilience and similar protective mechanisms (Benotsch et al., 2000; Lavee et al., 1985; McCubbin \& Dahl, 1976; McCubbin, Dahl, Lester, Benson, \& Robertson, 1976; 
McCubbin, Hunter, \& Dahl, 1975; McCubbin et al., 1980; McCubbin \& McCubbin, 1996; Patterson, 2002; Sutker et al., 1995; Thoits, 1983).

\section{Units of Analysis}

Life span theory is most commonly applied to the individual and family as the units of analysis (McCubbin et al., 1980). However, Erikson (1962, 1968, 1969) proposed that this theory could apply to humanity as an entity, thus not being limited to one's interactions with individuals, groups, or specific environments/institutions.

Subsequent theorists, such as Coles $(1990,1991,1997)$ and Strauss and Howe (1991), have focused on the more macro-level implications of Erikson's concepts, for example, in investigating human development within generations and religious reference groups.

Like life span theory, resiliency theory has been most commonly applied to individuals and family units that are consistent with these theories' shared developmental focus. More recent investigations of specific risk and protective factors, however, have shown a trend toward the examination of macro-level or contextual variables (Herrenkohl et al., 2003; Schafft, 2006; Smith-Osborne, 2005, 2006; Ungar, 2004), such as neighborhoods (e.g., disorganized, residentially unstable) and institutional policies.

\section{Aspects of Human Development}

Rapid advances in the knowledge base about the biological underpinnings of human development tend to lend support to conceptualizations of the life stages that are more fluid throughout the life span, rather than invariant or even necessarily sequential (Robbins et al., 1998; Thelen \& Smith, 1994). Incorporation of this new knowledge is seen most clearly in researchers who focus on adult development and aging. George Vaillant (1993), for example, pointed out that:

If adult development is to be conceived as a psychobiological process then it must conform to biology, and neither to social mores nor to chronological age. This means that, as with shaving and menstruation, not everybody will reach a given stage at the same chronological age (p. 166).

Similarly, Sharon McQuaide, in her research on "Women at Midlife" (1998), examined biological and cohort variables to add to life span theory. She found that "The generation of women now entering midlife differs from previous generations" (p. 21), and that women who were "'blocked from being in the world' (through disability, poor health, involuntary unemployment, limited spending power)" (p. 29) were less likely to achieve well-being and other indicators of generativity, Erikson's designation for the midlife stage issue. Life span theory, then, has the flexibility to address various aspects of human development throughout its stages.

Resiliency theory has, from its inception, been remarkable for encompassing the broad biopsychosocial aspects of human development, as well as for crossreferencing empirical findings on normative or healthy human development with findings on pathological development (Cichetti \& Cannon, 1999). Early develop- 
ment of the theory gave more attention to individual characteristics and to factors present in childhood, which were associated with adult outcomes, thus privileging enduring traits from earlier life stages. Although recent cross-sectional studies have begun to offer more possibilities for developing an understanding of resiliency in middle and later adulthood, this theory's current utility is, in its application to the broad aspects of human development, from infancy through early adulthood.

\section{Philosophical Underpinnings}

The life span theory philosophical underpinnings, most of which have been noted previously in this paper, include: a health and adaptation orientation, rather than a medical illness-oriented orientation; a special interest in the earlier stages of life; an ontogenetic perspective with emphasis on predictable and discontinuous life stages; a transition period between stages, which may be characterized by increased tension and disorganization (Erikson's "psychosocial crises"); an intrapsychic focus and an interactive focus; and lifelong development. As noted previously, the life span theorists who built on Erikson's work have gone far in addressing the limitations of many of these philosophical underpinnings, as well as the biases built into the original theory. Resiliency theory is characterized as similarly salutogenic, but with a philosophical orientation toward the linear, cumulative connections between earlier life stages and adulthood for those at risk. Resiliency research to date has been largely conducted by Western scientists and has had a linear, positivistic paradigm. Thus, it has been criticized as hegemonic and, thereby, limited in its scope in accounting for diverse resiliency experiences. Philosophically, resiliency theory is more heavily focused than life span theory on interactions between the environment and person in terms of environmental adversity and personal protective traits. As with life span theory, more recent work in resiliency theory has tipped the balance philosophically more in the direction of contextual protective variables, often operationalized as social groups and community and institutional characteristics.

\section{Strengths and Weaknesses}

The evident strengths of life span theory include its expansion of understanding of personality development through the life span, its utility across a variety of human service settings and functions, and its "generativity," to borrow Erikson's term and reapply it to theory-building. Life span theory gave rise to a rich plethora of human development models, not only to increase understanding of specific life stages or the entire life cycle, but also to address intermediate and macro-level entities, such as families, family-run businesses, social movements led by "great" personalities, faith communities and religious reference groups, and entire generational cohorts. In so doing, this theory has been applied to disciplines beyond the human service domain. For example, the sociological concept of the bourgeois bohemian (Brooks, 2001), the theological concept of Gen X religiosity (Beaudoin, 2000), and the economic concept of style as a form of self-expression (Postrel, 2003), all owe their origins ultimately to life span theory.

Several of the most cogent points of criticism of life span theory weaknesses have been noted above: the Euro-American, middle class, male bias; the rigidity 
of the life stage concept; and the notable lack of empirical support. Another, less frequently discussed weakness is the theory's failure to address or adequately explain the sources of the stage shifts (Haroutunian, 1983; Oyama, 1985) and the application of those stage shifts across domains (Thelen, 1987). Concomitantly, the theory has been targeted by critics for failure to account for the emergence of new forms in each stage (e.g., why do immobilized Hopi babies start walking at the same age as mobile WASP babies) in the context of the nature versus nurture dichotomy.

Resiliency theory shows promise as an emerging theory, which extends life span theory in offering predictive and explanatory constructs relevant to healthy development in the face of adversity. Its constructs and models have been used flexibly by social workers in concert with other theoretical perspectives, such as the ecosystems perspective (Fraser, 1997; Gilgun, 1997), systems theory (Ungar, 2004), the differential resiliency model (Palmer, 1997), and the social development model (Herrenkohl et al., 2003). Furthermore, this theory has demonstrated that it offers both a viable platform for developmental research and a conceptual framework capable of elegant and parsimonious evolution based on that research. Resiliency theory has the advantage of being empirically based from its inception and of thereby incorporating ongoing findings and constructs from biology and neuroscience, such as neuroplasticity (Rutter, 1999b). It has begun to demonstrate utility in application across human service settings and practice models and across life stages and trajectories (Greene, 2007).

One important limitation of resiliency theory is its restriction to application only to populations in adversity or populations experiencing trauma or high stress levels. Theoretical constructs may be misapplied in research or practice to normative life cycle issues or moderately stressful events. The constructs themselves have been criticized as tautological and are inconsistently defined across studies, thus limiting validity and reliability of the research. Considerable effort has been made by leading resiliency theorists, particularly in the last decade, to clarifying and standardize these definitions. This theory has also been criticized for its positivist research paradigm to date, with consequential bias towards linear explanatory models based on predictable, hierarchical relationships between protective and risk factors (Ungar, 2004). This tendency may limit its utility in application to diverse cultures and populations. On the other hand, the original empirical basis for the development of the theory consisted heavily of studies of cross-cultural and ethnic minority populations, which may be evidence to counter this criticism.

\section{Empirical Support}

Life span theory has been criticized as lacking an empirical base of support, much like psychodynamic theory in general has been criticized. It is true that many theorists in this perspective use clinical case and cross-cultural observation (Erikson, 1968; Coles, 1990; Greenspan, 1992) and, in some instances, examination of the lives of great men and women, as their primary methodology for generating the theory. For example, Erikson studied the lives of Luther and Gandhi $(1962,1969)$, while Vaillant looked at Florence Nightingale's life in his analysis of women's adult development (Vaillant, 1993). Coles is robust in his defense of these clinically ori- 
ented methodologies in generating rich, contextually-based theoretical constructs, and is critical of the biases and limitations he finds inherent in empirical, quantitative methodologies (1990, pp. 22-39).

However, Vaillant's longitudinal study of adult men (1977), his follow-up study of male adults from a different socioeconomic group (1993), and recent quantitative studies of adult development (McQuaide, 1998; Norman, McCluskeyFawcett, \& Ashcraft, 2002) have provided empirical support both for the life span concepts derived from ego defense theory and for life stage concepts.

In general, the life span theory has maximal utility when used to describe and explain the human development of individuals and, at a probabilistic rather than prescriptive level (Robbins et al., 1998). Erikson indicated his general concurrence with this summation in his discussion of the misapplication of his concept of the psychosocial crisis (1968, pp. 15-43).

As previously described in this paper, resiliency theory has been conceived on an empirical basis, with two examples being Werner and Smith's study of infants in Hawaii and the English and Romanian Adoptees Study Team's investigation of institutionalized children who were later adopted (Rutter, Quinton, \& Hill, 1990; Rutter \& ERA, 1998). Resiliency theory-based empirical findings have been useful in refining important practice modalities used in social work. For example, such findings suggested a shift in the focus on family therapy to include assessment of the differential impact of family communication patterns on different family members, depending on individual vulnerability factors and peer group influences (Rutter, 1999b; Greene, 2007). Richardson (2002) has suggested that there have been three waves of resiliency research: the first wave focused on identifying resilient qualities in person and environment, the second wave focused on specifying resilient processes effective in overcoming the odds, and the third and current wave in identifying innate transformational processes. Empirical testing of resiliency constructs and models is ongoing in several disciplines, including social work (e.g., Finkelstein et al., 2005; Hrabowski, Freeman, Maton, \& Greif, 1998, 2002; Kennedy, 2005; Wright, Fopma-Loy, \& Fischer, 2005).

\section{IMPLICATIONS FOR SOCIAL WORK}

\section{Consistency with Social Work Values}

Despite its lack of empirical evidence, life span theory has enjoyed widespread acceptance, not only among social workers, but among the wide range of human service disciplines, particularly those with a psychodynamic theoretical perspective regardless of discipline. Thus, part of its appeal has come from its expansion of Freudian theory and its correction of some of the limitations and biases of that theory. Its optimistic, strengths-oriented perspective, and its applicability to some domains other than the individual (McCubbin et al., 1980) have shown consistency with social work values. The utility of its concepts and theoretical constructs has been amply demonstrated by the variety and magnitude of applications that have been made to practice issues (e.g., Streever \& Wodarski, 1984; Snow, 2003; Smith-Osborne, 2005b), to theory building (e.g., Elder, 1998; George, 1993; Ingersoll-Dayton, Krause, \& Morgan, 2002; Vaillant, 1993), and to popular 
understanding of the nature of human life (e.g., Sheehy, 1976). The psychodynamic life span theorists deemphasized the biological determinism of strict Freudian theory, and their theoretical concepts focus on successful negotiation of the life stage transitions as a normative, not as pathological process. These factors are seen as consistent with social work values, such as client self-determination and strengths-based practice.

Contemporary social workers are cautioned to be mindful that the originators of this theory base operated almost exclusively within a Euro-American middle class framework, which limits the utility of the theory for application to diverse cultures and classes. The male bias inherent in the original theory base has been partially addressed through research and additional theory formulation on the development of women through the life span (Gilligan, 1978, 1982, 1991; Friedan, 1963, 1977; and 1993; McQuaide, 1998).

The social work emphasis on person-in-environment is a good fit with life span theory's perspective of human development as proceeding interactively. The limitations of the theory in taking macro-level influences into account, and the expansion work in this area by Strauss and Howe and others, is noted above.

Resiliency theory shares with life span theory the excellent fit with social work values detailed above, while avoiding the cultural, class and gender biases that have been noted in life span theory. Its focus on vulnerability and populations at risk makes it particularly useful to the social work mission. This theory has been criticized as being less consistent with social work values than it could be, due to the hegemonic tendencies inherent in its positivistic philosophical underpinnings; however, new qualitative and mixed methods research, undertaken within a constructivist paradigm, may develop this theory so as to correct these tendencies.

\section{Next Steps for Theory Progression}

The current status of life span theory within social work remains that of widespread, even uncritical acceptance in its application, in a variety of human service settings, from child welfare agencies to parent education classes. Social workers who practice or conduct research with specific age groups are informed by this theory in understanding the unique aspects of that age group or birth cohort (e.g., McQuaide, 1998; Norman et al., 2002). In social work education, it is taught in theory and human behavior classes at all levels of social work preparation. The concept of developmental stages has been applied to student development through the field instruction process in social work, as well as in counseling and psychology (Deal, 2000, 2002). The utility of this theoretical perspective and its value-fit with the social work profession are likely to ensure its continued place within the discipline. In order to enhance its viability as a foundation for best practices, life span theory must take the next steps in theory progression by strengthening empirical support for both its micro and macro levels across life stages, including the incorporation of recent advances in human neuroscience evidence. Further development of models for middle and older adult life stages, differentiated by gender and ethnicity, is also needed. Continued attention must be paid to the dissemination of updated life span theory development by social work educators, text writers, and researchers. 
The current status of resiliency theory in social work is that of an emerging theory; its main constructs are used more often than the entire, articulated theoretical framework, both in social work research and education, while frequency of practitioners' use of this theory and its evidence base is unclear. Since it represents an extension of more well-established life span theory and shares many of that theory's strengths and acceptability for the profession, it is likely that resiliency theory will become more widely used in social work education the near future, as indicated by its use in at least two recently published texts in the Human Behavior in the Social Environment curriculum (Greene, 2007; Haight \& Taylor, 2007). The next steps for progression of this theory should include cross-sectional studies to elucidate applicability of the known protective mechanisms to young adult, middle adult, and older adult life stages, and to generational cohorts. Cross-sectional and longitudinal studies are needed to examine the operation of protective and risk mechanisms for particular resilient outcomes, such as educational attainment, health disparities and perceived level of wellness, quality of life, and vocational achievement, to build on results of the most common, previously studied outcome of psychopathology versus mental wellness. Qualitative and mixed methods research designs must be applied to extend theory development to diverse cultures and perceived operationalizations of resiliency within the lived experience of persons across the life span and across conditions of adversity. Further discussion is needed in the literature to refine the operationalization of this theory's constructs and models and to promote common usage of the same in research. Articulation of practice applications of the theory, followed by empirical testing of related interventions, is necessary to integrate this theory into our understanding of human behavior in the social environment and to add to the evidence base for practice with populations in adversity.

Resiliency theory offers a rich opportunity for social work to refine evidencebased developmental theory for the vulnerable populations it is our unique privilege to serve.

\section{References}

Beaudoin, T. (1998). Virtual faith: The irreverent spiritual quest of Generation X. San Francisco: JosseyBass.

Brooks, D. (2001). Bobos in paradise. New York: Touchstone.

Cannon, T.D., Rosso, I.M., Bearden, C.E., Sanchez, L.E., \& Hadley, T. (1999). A prospective cohort study of neurodevelopmental processes in the genesis and epigenesist of schizophrenia. Development and Psychopathology, 11(1), 467-485.

Cichetti, D., \& Cannon, T.D. (1999). Neurodevelopmental processes in the ontogenesis and epigenesis of psychopathology. Development and Psychopathology, 11, 375-393.

Colby, V. (1970). The singular anomaly. New York: New York University Press.

Coles, R. (1990). The spiritual life of children. Boston: Houghton Mifflin Company.

Coles, R. (1991). The moral life of children. Boston: Houghton Mifflin Company.

Coles, R. (1997). The moral intelligence of children. New York: Random House. 
Daining, C. (2005). Resilience of youth in transition from out-of-home care to adulthood. Unpublished dissertation, University of Maryland, Baltimore.

Darwin, C. (1872). The expression of emotions in man and animal. New York: Philosophical Library.

Deal, K.H. (2000). The usefulness of developmental stage models for clinical social work students: An exploratory study. The Clinical Supervisor, 19(1), 1-19.

Deal, K.H. (2002). Modifying field instructors' supervisory approach using stage models of student development. Journal of Teaching in Social Work, 22(3/4), 121-137.

DeForge, B., Belcher, J., O’Rourke, M., \& Lindsey, M. (2005). Personal resources and homelessness in early life: Predictors for depression in consumers of homeless multi-serviced centers. Manuscript submitted for publication.

D'Imperio, R.L., Dubow, E.F., \& Ippolito, M.F. (2000). Resilient and stress-affected adolescents in an urban setting. Journal of Clinical Child Psychology, 29, 129-142.

Dubow, E.F., Schmidt, D., McBride, J., Edwards, S., \& Merk, F.L. (1993). Teaching children to cope with stressful experiences: Initial implementation and evaluation of a primary prevention program. Journal of Clinical Child Psychology, 22, 428-440.

Dubow, E.F., Tisak, J., Causey, D., Hryshko, A., \& Reid, G. (1991). A two-year longitudinal study of stressful life events, social support, and social problem-solving skills: Contributions to children's behavioral and academic adjustment. Child Development, 62, 583-599.

Elder, G.H. (1998). The life course and human development. In W. Damon \& R.M. Lerner (Eds.), Handbook of Child Psychology ( $5^{\text {th }}$ ed., pp. 939-983). New York: John Wiley \& Sons, Inc.

Erikson, E. (1962). Young man Luther: A study in psychoanalysis and history. New York: Norton.

Erikson, E.H. (1963). Childhood and society ( $2^{\text {nd }}$ ed., Rev.). New York: W.W. Norton \& Co., Inc.

Erikson, E.H. (1968). Identity: Youth and crisis. New York: W.W. Norton \& Co., Inc.

Erikson, E.H. (1980). Identity and the life cycle. New York: W.W. Norton \& Co., Inc.

Erikson, E.H. (1969). Gandhi's truth: On the origins of militant nonviolence. New York: Norton.

Freud, S. (1905). Three essays on the theory of sexuality. In (Ed.), The Standard Edition of the Complete Psychological Works of Sigmund Freud (vol. 7 ed., pp. 125-145). London: Hogarth.

Friedan, B. (1963). The feminine mystique. New York: Dell.

Friedan, B. (1977). It changed my life. New York: Dell.

Friedan, B. (1993). The fountain of age. New York: Simon \& Schuster.

Garmezy, N. (1991). Resiliency and vulnerability to adverse developmental outcomes associated with poverty. American Behavioral Scientist, 34, 416-430.

Garmezy, N., \& Rutter, M. (Eds.). (1983). Stress, coping, and development in children. New York: McGrawHill Book Company.

George, L.K. (1993). Sociological perspectives on life transitions. Annual Review of Sociology, 19, 353-373.

Gesell, A.L. (1925). The mental growth of the preschool child. New York: Macmillan.

Gilligan, C. (1978). Woman's place in man's life cycle. Harvard Educational Review, 49, 481-517.

Gilligan, C. (1982). In a different voice: Psychological theory and women's development. Cambridge, MA: Harvard University Press.

Gilligan, C., Rogers, A.G., \& Tolman, D.L. (Eds.). (1991). Women, girls and psychotherapy: Reframing resistance. New York: The Haworth Press, Inc.

Goffman, E. (1959). The presentation of self in everyday life. Garden City, NY: Doubleday.

Greene, R.R. (2007). Social work practice: A risk and resilience perspective. Belmont, CA: Thomson Brooks/Cole.

Greenspan, S.I. (1992). Infancy and early childhood: The practice of clinical assessment and intervention with emotional and developmental challenges. Madison, CT: International Universities Press, Inc. 
Gunnar, M.R., \& Thelen, E. (Eds.). (1989). Systems and development: The Minnesota symposia on child psychology, vol. 22. Hillsdale, New Jersey: Lawrence Erlbaum Associates, Inc.

Haight, E.H., \& Taylor, M. (Eds.). (2007). The life and letters of James Monroe Taylor: The biography of an educator. (Sixth edition). New York: The Columbia Encyclopedia, E.P. Dutton and Co.

Hall, G.H. (1904). Adolescence: Its psychology and its relations to physiology, anthropology, sociology, sex crime, religion, and education. New York: Appleton \& Co.

Haroutunian, S. (1983). Equilibrium in the balance: A study of psychological explanation. New York: Springer-Verlag.

Herrenkohl, T.I., Hill, K.G., Chung, I., Guo, J., Abbott, R.D., \& Hawkins J.D. (2003). Protective factors against serious violent behavior in adolescence: A prospective study of aggressive children. Social Work Research, 27, 179-191

Hoffman, L., Paris, S., Hall, E., \& Schell, R. (1988). Developmental psychology today $\left(5^{\text {th }}\right.$ ed.). New York: McGraw-Hill, Inc

Holleran, L.K., Kim, Y., \& Dixon, K. (2004). Innovative approaches to risk assessment within alcohol prevention programming. In A.R. Roberts \& K.R. Yeager (Eds.), Evidence-based practice manual: Research and outcome measures in health and human services (pp. 677-684). New York: Oxford University Press.

Hrabowski, I., Freeman A., Maton, K.I., Greene, M.L., \& Greif, G.L. (2002). Overcoming the odds: Raising academically successful African-American young women. New York: Oxford University Press.

Hrabowski, I., Freeman A., Maton, K.I., \& Greif, G. L. (1998). Beating the odds: Raising academically successful African American males. New York: Oxford University Press.

Ingersoll-Dayton, B., Krause, N., \& Morgan, D. (2002). Religious trajectories and transitions over the life course. International Journal on Aging and Human Development, 55(1), 51-70.

Jackson, Y., \& Warren, J.S. (2000). Appraisal, social support, and life events: Predicting outcome behavior in school-age children. Child Development, 71, 1441-1457.

Jew, C.L., Green, K.E., \& Kroger, J. (1999). Development and validation of a measure of resiliency. Measurement \& Evaluation in Counseling \& Development, 32, 1-15.

Jung, C.G. (1965). Memories, dreams, and reflections. New York: Vintage Books.

Karl, F.R. (1964). A reader's guide to the nineteenth century novel. New York: H. Woolff.

Knox, D., Langehough, S.O., Walters, C., \& Rowley, M. (1999). Religiosity and spirituality among college students. College Student Journal, 33, 430-432.

Lam, D. (1999). Parenting stress and anger: The Hong Kong experience. Child and Family Social Work, 4, 337-346.

Lavee, Y., McCubbin, H.I., \& Patterson, J. (1985). The double ABCX model of family stress and adaptation: An empirical test by analysis of structural equations with latent variables. Journal of Marriage and the Family, 47, 811-825.

Lazarus, R.S. (1993). From psychological stress to the emotions: A history of changing outlooks. Annual Review of Psychology, 44, 1-21.

Lazarus, R.S., \& Folkman, S. (1984). Stress, appraisal, and coping. New York: Springer.

LeCuyer-Maus, E.A. (2003). Stress and coping in high-risk mothers: Difficult life circumstances, psychiatric-mental health symptoms, education, and experiences in their families of origin. Public Health Nursing, 20, 132-145.

Longo, D.A., \& Peterson, S.M. (2002). The role of spirituality in psychosocial rehabilitation. Psychosocial Rehabilitation Journal, 25, 333-340.

Luthar, S., Cicchetti, D., \& Becker, B. (2000). The construct of resilience: A critical evaluation and guidelines for future work. Child Development, 71, 543-562.

Macias, M.M., Clifford, S.C., Saylor, C.F., \& Kreh, S.M. (2001). Predictors of parenting stress in families of children with spina bifida. Children's Health Care, 30, 57-65.

Marcia, J.E. (1980). Identity in adolescence. In J. Adelson (Ed.), Handbook of adolescent psychology (pp. 159-187). New York: Wiley-Interscience. 
Masten, A.S., \& Coatsworth, J.D. (1998). The development of competence in favorable and unfavorable environments: Lessons from research on successful children. American Psychologist, 53, 205-220.

McCubbin, H.I., \& Dahl, B.B. (1976). Prolonged family separation in the military: A longitudinal study. In H.I. McCubbin, B.B. Dahl \& E.J. Hunter (Eds.), Families in the military system. Beverly Hills, CA: Sage.

McCubbin, H.I., Dahl, B.B., Lester, G.R., Benson, D., \& Robertson, M.L. (1976). Coping repertoires of families adapting to prolonged war-induced separations. Journal of Marriage and the Family, 38, 461-471.

McCubbin, H.I., Hunter, E.J., \& Dahl, B.B. (1975). Residuals of war: Families of prisoners of war and servicemen missing in action. Journal of Social Issues, 31, 95-109.

McCubbin, H.I., Joy, C.B., Cauble, A.E., Comeau, J.K., Patterson, J.M., \& Needle, R.H. (1980). Family stress and coping: A decade review. Journal of Marriage \& the Family, 42(4), 855-871.

McCubbin, M.A., \& McCubbin, H.I. (1996). Resiliency in families: A conceptual model of family adjustment and adaptation in response to stress and crises. In H.I. McCubbin, A.I. Thompson, \& M.A. McCubbin (Eds.), Family assessment: Resiliency, coping, and adaptation-Inventories for research and practice (pp. 1-64). Madison, Wisconsin: University of Wisconsin System.

McGee, M., Nagel, L., \& Moore, M.K. (2003). A study of university classroom strategies aimed at increasing spiritual health. College Student Journal, 37, 583-594.

McQuaide, S. (1998). Women at midlife. Social Work, 43(1), 21-30.

Morrison, G.M., Robertson, L., Laurie, B., \& Kelly, J. (2002). Protective factors related to antisocial behavior trajectories. Journal of Clinical Psychology, 58, 277-290.

Murray, C. (2003). Risk factors, protective factors, vulnerability, and resilience: A framework for understanding and supporting the adult transitions of youth with high-incidence disabilities. Remedial and Special Education, 24, 16-26.

Musil, C.M. (2000). Health of grandmothers as caregivers: A ten-month follow-up. Journal of Women \& Aging, 12, 129-145.

Naerde, A., Tambs, K., \& Mathiesen, K.S. (2002). Child-related strain and maternal mental health: A longitudinal study. Acta Psychiatrica Scandinavica, 105, 301-309.

Neugarten, B.L. (1985). Interpretive social science and research on aging. In A.S. Rossi (Ed.), Gender and the life course (pp. 291-300). New York: Aldine.

Newman, B.M., \& Newman, P.R. (1975). Development through life: A psychosocial approach. Homewood, IL.: The Dorsey Press.

Norman, S.M., McCluskey-Fawcett, K., \& Ashcraft, L. (2002). Older women's development: A comparison of women in their 60s and 80s on a measure of Erikson's developmental tasks. International Journal on Aging and Human Development, 54, 31-41.

Norman, W.H., \& Scaramella, T.J. (Eds.). (1980). Mid-life: Developmental and clinical issues. New York: Brunner/Mazel.

Oyama, S. (1985). The Ontogeny of information: Developmental systems and evolution. Cambridge, England: Cambridge University Press.

Patterson, G.T. (2003). Examining the effects of coping and social support on work and life stress among police officers. Journal of Criminal Justice, 31, 215-226.

Patterson, J.M. (2002). Integrating family resilience and family stress theory. Journal of Marriage and Family, 64, 349-360.

Postrel, V. (2003). The substance of style. New York: Harper Collins.

Quamma, J.P., \& Greenberg, M.T. (1994). Children's experience of life stress: The role of family social support and social problem-solving skills as protective factors. Journal of Clinical Child Psychology, 23, 295-305

Richardson, G.E. (2002). The metatheory of resilience and resiliency. Journal of Clinical Psychology, 58, 307-321.

Robbins, S.P., Chatterjee, P., \& Canda, E.R. (1998). Contemporary human behavior theory. Needham Heights, MA: Allyn \& Bacon. 
Rolf, J., Masten, A.S., Cicchetti, D., Nuechterlein, H.H., \& Weintraub, S. (Eds.). (1990). Risk and protective factors in the development of psychopathology. Cambridge, England: Cambridge University Press.

Rutter, M. (1983). Cognitive deficits in the pathogenesis of autism. Journal of Child Psychology and Psychiatry, 24, 513-531.

Rutter, M. (1987). Psychosocial resilience and protective mechanisms. American Journal of Orthopsychiatry, 57, 316-331.

Rutter, M. (1993). Resilience: Some conceptual considerations. Journal of Adolescent Health, 14, 626-631.

Rutter, M. (1999a). Psychosocial adversity and child psychopathology. The British Journal of Psychiatry, $174,480-493$.

Rutter, M. (1999b). Resilience concepts and findings: Implications for family therapy. Journal of Family Therapy, 21, 119-144.

Rutter, M., \& the English \& Romanian Adoptees (ERA) Study Team. (1998). Developmental catch-up, and deficit, following adoption after severe global early privation. Journal of Child Psychology and Psychiatry, 39, 465-476.

Rutter, M., Quinton, D., \& Hill, J. (1990). Adult outcomes of institution-reared children: Males and females compared. In L.N. Robins \& M. Rutter (Eds.). Straight and devious pathways from childhood to adulthood (pp. 135-157). Cambridge: Cambridge University Press.

Saltman, J.E. (2002). Theory and practice in social work: Two perspectives on reality. Arete, 26, 84-99.

Saltman, J.E.E., \& Greene, R.R. (1993). Social workers' perceived knowledge and use of human behavior theory. Journal of Social Work Education, 29, 88-98.

Santrock, J.W. (1989). Life span development ( $3^{\text {rd }}$ ed.). Dubuque, IA: W.C. Brown.

Schafft, K.A. (2006). Poverty, residential mobility, and student transiency within a rural New York school district. Rural Sociology, 71, 212-231.

Shanahan, M.J. (2000). Pathways to adulthood in changing societies: Variability and mechanisms in life course perspective. Annual Review of Sociology, 26, 667-692.

Sheehy, G. (1976). Passages. New York: E.P. Dutton \& Co., Inc.

Smith, C., \& Carson, B.E. (1997). Stress, coping, and resilience in children and youth. Social Service Review, 6, 231-256.

Smith, P.L. (2003). Adaptive coping strategies of other mothers: An examination of social support, spirituality, stress, and depression. University of Maryland Baltimore: Unpublished doctoral dissertation.

Smith-Osborne, A. (2005a). Antecedents to postsecondary educational attainment for individuals with psychiatric disorders: A meta-analysis. Best Practices in Mental Health: An International Journal, 1, 1530.

Smith-Osborne, A. (2005b). Comparative theoretical perspectives on a social problem: Psychopathology and middle-class teen female shoplifters. Journal of Evidence-Based Social Work, 2, 73-84.

Smith-Osborne, A. (2006). Mental health risk factors and protective mechanisms for post-secondary educational attainment among young adult veterans. Unpublished doctoral dissertation, University of Maryland at Baltimore.

Smith-Osborne, A. (in press). Use of meta-analysis to study resilience factors: An exemplar. In M. Unger \& L. Liebenberg (Eds.), Researching youth across cultures and contexts. Toronto, CA.: University of Toronto Press.

Stanton-Salazar, R.D., \& Spina, S.U. (2000). The network orientations of highly resilient urban minority youth: A network-analytic account of minority socialization and its educational implications. The Urban Review, 32, 227-261.

Strauss, W., \& Howe, N. (1991). Generations: The history of America's future, 1584-2069. New York: William Morrow.

Streever, K.L., \&Wodarski, J.S. (1984). Life span developmental approach: Implications for practice. Social Casework: The Journal of Contemporary Social Work, 267-278.

Sutker, P.B., Davis, J.M., Uddo, M., \& Ditta, S.R. (1995). War zone stress, personal resources, and PTSD in Persian Gulf War returnees. Journal of Abnormal Psychology, 104, 444-452. 
Thelen, E. (1987). We think, therefore we move. Current Psychology of Cognition, 7, 195-198.

Thelen, E., \& Smith, L.B. (1994). A dynamic systems approach to the development of cognition and action. Cambridge, MA: The MIT Press.

Thoits, P.A. (1983). Life stress, social support, and psychological vulnerability: Epidemiological considerations. Journal of Community Psychology, 10, 341-362.

Unger, Michael. (2004). A constructionist discourse on resilience: Multiple contexts, multiple realities among at-risk children and youth. Youth \& Society, 35, 341-365.

Vaillant, G.E. (1977). Adaption to life. Boston: Little, Brown, \& Co.

Vaillant, G.E. (1993). The wisdom of the ego. Cambridge, MA: Harvard University Press.

Werner, E.E., \& Smith, R.S. (1992). Overcoming the odds: High risk children from birth to adulthood. Ithaca, NY: Cornell University Press.

West, L., Mercer, S.O., \& Altheimer, E. (1993). Operation Desert Storm: The response of a social work outreach team. Social Work in Health Care, 19, 81-98.

Winterowd, C.L., Street, V.L., \& Boswell, D.L. (1998). Perceived social support, disability status, and affect in college students. Journal of College Student Psychotherapy, 13, 53-70.

\section{Author's Note:}

Address correspondence to: Alexa Smith-Osborne, Ph.D., assistant professor, The University of Texas at Arlington School of Social Work, 211 S. Cooper, Box 19129, Arlington, TX 76019, USA. e-mail: alexaso@uta.edu. 